\title{
Exergy analysis of different solutions for humidity control in heritage buildings
}

\author{
M. Molinari ${ }^{1, *}$, T. Broström ${ }^{2}$, \\ ${ }^{1}$ KTH, Stockholm, Sweden \\ ${ }^{2}$ Gotland University, Gotland, Sweden \\ *Corresponding author.Tel: +4687909026,E-mail: marco.molinari@byv.kth.se
}

\begin{abstract}
Energy use in the building stock represents a major contribution to the total energy use in developed countries. Increasing limitations to the energy demand of the new buildings have been imposed by the building codes in the last decades, which resulted in improved building envelopes.

Yet, in many cases it is not either technically or economically feasible to improve the existing building shells. A typical example is represented by historical buildings, such churches and old buildings, which often may not be improved for aesthetical or economic reasons. Often poorly insulated, such buildings would require a high energy demand to keep them at the preferable hygro-thermal conditions. As a consequence they are often left unheated, which also affects the usability of these buildings. However, the risk of moisture damage often requires them to be slightly heated to a certain temperature.

As the energy demand is linked to the possibility of improving the building shell, for instance by adding insulation or making it more airtight, the exergy approach gives interesting insights on the problem. Exergy analysis emphasizes the thermodynamic valuable part of the energy demand in the building and straightforwardly defines the minimum energy demand for a certain process. The energy demand being equal, it is still possible to lower the exergy demand and consumption. A lower exergy demand paves the way to the exploitation of renewable sources, such as solar power.

Often the main task is to keep the RH humidity within a certain range. Aim of this paper is to perform a theoretical exergy analysis of three different solutions for lowering the RH in the building. The basic approach keeps the temperature of the indoor space at a constant level. A second approach-the so-called conservation heating- consists in letting the temperature vary according to the maximum allowed indoor relative humidity. In the third case the target is reached by means of a dehumidification process. Advantages and disadvantages of the different approaches are shown under the energy and exergy points of view.

The present research is done within the framework of the "Spara och bevara" project, which targets cost-efficient solutions for the conservation and the use of heritage buildings in Sweden and the IEA Annex49 and ESF COSTexergy projects, which aim at energy-efficient buildings and communities through the application of the low-exergy approach.
\end{abstract}

Keywords: Exergy analysis, Energy efficient buildings, Heritage buildings, Renewable energy.

\section{Nomenclature}

$E x_{s, \text { th }}$ thermal specific exergy ......................J/kg

$E x_{s, t h}$ chemical specific exergy...................J/kg

$R_{a} \quad$ ideal gas constant for air.............. J/( $\left.\mathrm{kgK}\right)$

$T_{i} \quad$ room temperature ....................................

$T_{0} \quad$ environment temperature .........................

\section{Introduction}

In European countries, residential and commercial buildings are the sector with the largest share of primary energy use, $25 \%$ (1) and a relevant share of that is supplied by fossil fuels. The reduction of the energy demand and the exploitation of renewable energy sources has then become a priority in the EU political agenda. A widely used approach to reduce the energy demand in buildings is to improve their thermal insulation. While cost-effective during the construction phase of the building, this approach is expensive in existing buildings and alternative strategies should then be applied. The reduction of the quality of the energy supply in buildings is recognized as beneficial to reduce the environmental impact due to the energy use in buildings. An effective tool to quantify the quality of energy is exergy. 
The IEA ECBCS Annex 37 (2) and the IEA ECBCS Annex 49 (3) showed that a $g$ reat potential for improving the energy use in buildings resides in lowering the energy quality, i.e. the exergy, in buildings. A relevant share of the energy demand is represented by space heating and domestic hot water, (4) and (5), which is energy with low quality; buildings have a high energy demand but a low exergy demand. In contrast to this they are often supplied with valuable energy sources, such as direct electricity heating and gas. The exergy analysis applied to buildings explains how to use the energy in a more rational way by reducing the exergy losses, i.e. the energy quality mismatch between sources and end-use energy. This reduction can be obtained by supplying the building demand with degraded forms of energy, such as waste and low-temperature heat, that would be unsuitable for high-exergy processes, which occur for example in industry and transportation.

The application of the low exergy approach benefits also the exploitation of renewable sources. Renewable energy supplies have often low specific power. So-called low-exergy systems are systems with low temperatures and therefore low specific power. A floor heating, for instance, has low emission temperatures and lower emission power per unit area than radiators. It is therefore suitable for low supply temperatures, i.e. low exergy supply, such as energy from ground heat storages or from solar panels.

Optimized low-exergy systems need to be integrated and require a holistic approach. A prerequisite to an improved use of energy is to perform an exergy analysis of the system demand to highlight what is the potential for improving the overall system. In the present paper, exergy analysis was applied to the specific case of the historical buildings.

In such buildings the control of the relative humidity, $\mathrm{RH}$, is important to decrease the risk of formation of mould and condensation. The lowering of RH can be obtained by heating, i.e. increasing the temperature of the air, or by dehumidifying, i.e. decreasing the water vapor contained in the unit mass of air. A common process in dehumidification consists in decreasing the air temperature needs below the dew-point, to condense the water vapor, and then to reheat it, thus making the process energy demanding.

Aim of this paper is to explore the potential for the reduction of the relative humidity. Three different approaches have been chosen and analyzed exergy-wise in two different Swedish locations.

\section{Methodology}

Exergy is defined as the maximum work that can theoretically be extracted by a device working between two states in non-equilibrium. When temperature, pressure and chemical composition are the same as the surroundings, thermodynamic equilibrium is reached and no more work can be extracted. These conditions are called dead-state. For buildings, the surroundings are represented by the environment and the dead-state conditions, often called reference conditions, are represented by environment temperature, pressure and chemical composition. In buildings exergy analysis the chemical composition regards the moisture content of the air, which some studies have shown to affect in a relevant way the exergy calculation, especially in warm and humid climates, (6) and(7).

In the present paper, exergy analysis has been applied to the three strategies for reducing the risks of condensation in historical buildings. An upper limit of $70 \% \mathrm{RH}$ has been considered safe in this paper, following the approach used in (8). The building has been modeled into indoor room space and outdoor environment, whose conditions represent the so-called reference state. 
To reach certain set-point conditions of the indoor air, a flow of exergy has to be supplied. The minimum flow needed is determined by the physical conditions of the unit air, i.e. the exergy content per unit mass. The minimization of the exergy content is the necessary prerequisite to the decrease of the exergy demand. The air exergy content resulting from the different strategies to lower the RH has then been compared. This approach allows to keep a general approach that can be applied to several types of buildings and also to benchmark the expected performance of the different strategies in terms of exergy.

Two different Swedish locations have been simulated, Gothenburg and Östersund. Gothenburg is located on the southwest coast of Sweden (latitude $57^{\circ} 43^{\prime}$ ) and it has a coastal climate with high RH most of the year. Östersund is located in the middle of Sweden (latitude $63^{\circ}$ ) and it has an inland climate, considerably colder than Gothenburg.

The first strategy is the background heating, which consists in keeping the indoor temperature at $12{ }^{\circ} \mathrm{C}$ by providing heat to the room. If the ambient temperature is higher than this set-point temperature, the building is left unheated.

The second strategy is the so-called conservation heating, which consists in the use of heating to keep the internal humidity under a certain level above which the risk of mould formation is considered to increase consistently. This target relative humidity, which in this paper is set to $70 \%$ (8), is kept by raising the indoor temperature. As the temperature increases, the saturation pressure of the water vapor decreases, i.e. the air is capable to dilute more vapor, and so does the relative humidity decreases. When the indoor $\mathrm{RH}$ was higher than the $70 \%$ set-point, then the indoor temperature was set to the value corresponding to this RH set-point, by calculating the saturation pressure of the vapor. When the RH was lower than the RH setpoint, no change in the indoor temperature took place.

In the third case, the target relative humidity is kept to $70 \%$ by dehumidification. This process is usually done by decreasing the temperature of the air under the dew-point, condition at which the water contained in the air starts to condense. By removing it and post-reheating it the air becomes drier. The exergy content in an ideal dehumidification process (9) was calculated when the RH was higher than the $70 \%$ set-point.

In the second and the third strategy, indoor thermo-hygrometric conditions have also been investigated for two different levels of internal moioture generation, $\Delta v=1 \mathrm{~g} / \mathrm{m}^{3}$ and $\Delta \mathrm{v}=2$ $\mathrm{g} / \mathrm{m}^{3}$, with $\Delta \mathrm{v}\left(\mathrm{g}_{\text {vapor }} / \mathrm{m}^{3}\right.$ air $)$ being the humidity added from the building structure.

In the Table 1 a summary of the set-points for $\mathrm{RH}$ and temperatures are shown for the different strategies. 
Table 1: Summary of temperature and RH set-points in the different strategies. The temperature in the constant temperature heating is kept at $12^{\circ} \mathrm{C}$ or higher in warmer seasons. In the conservation heating strategy, the values of the internal temperature depends on the relative humidity. In the dehumidification strategy, the temperature in the room is the same as the environment.

\begin{tabular}{ccc}
\hline Strategy & Room set-point temperature $\left[{ }^{\circ} \mathrm{C}\right]$ & Room set-point RH [\%] \\
\hline Constant temperature & 12 & - \\
heating & & 70 \\
Conservation heating & Dependent on RH & 70 \\
Dehumidification & - & \\
\hline
\end{tabular}

The expressions for the calculations of the specific exergy have been derived from (7) and (9):

$$
\begin{aligned}
& E x_{s, t h}=\left(c_{p_{a}}+\omega_{i} c_{p v}\right) T_{0}\left(\frac{T_{i}}{T_{0}}-1-\ln \left(\frac{T_{i}}{T_{0}}\right)\right) \\
& E x_{s, c h}=R_{a} T_{0}\left(\left(1+1.608 \omega_{i}\right) \ln \left(\frac{1+1.608 \omega_{0}}{1+1.608 \omega_{i}}\right)+1.608 \omega_{i} \ln \left(\frac{\omega_{i}}{\omega_{0}}\right)\right)
\end{aligned}
$$

In the equation (1) $E x_{s, t h}$ is the thermal specific exergy, $T_{i}$ is the ambient temperature, $T_{0}$ is the environment temperature and $c_{p}$ is the specific heat capacity of the air. In the equation (2) $E x_{s, c h}$ is the chemical specific exergy, $R_{a}$ is the ideal gas constant for air, $T_{0}$ is the environment temperature, 1.608 represents the molar mass of air to that of water vapor, $\omega_{i}$ is the humidity ratio of the room and $\omega_{0}$ is the humidity ratio of the environment. The air exergy content of the three different strategies have been calculated with time-steps of 1 hour for a whole year. This simplified model doesn't take into account the moisture storage in the structure; the structure itself acts as $\alpha$ constant moioture generotor $\left(\Delta v=1\right.$ ond $\left.\Delta v=2 \mathrm{~g} / \mathrm{m}^{3}\right)$. The exergy calculated in each time-step is then the exergy needed to keep the air in conditions of temperature and humidity considered safe to avoid condensation and mould growth.

\section{Results}

In Figure 1, the average monthly values of the temperature and the relative humidity, derived from the hourly calculations, are displayed. The temperatures are plotted for all the analyzed cases; the simulations of the conservation heating otrategy are ohown for the different $\Delta v$ (cases $2 \mathrm{a}, 2 \mathrm{~b}$ and $2 \mathrm{c}$ ). The $\mathrm{RH}$ is the same in all the simulations of the case 2 due to the $\mathrm{RH}$ control strategy. The environment $\mathrm{RH}$ is above the $70 \%$ limit for most of the year. The constant temperature heating strategy (Case 1) has an indoor temperature constantly set to 12 ${ }^{\circ} \mathrm{C}$, except in oummertime, when it i $\sigma$ higher. This strategy decreases the moisture to very low levels in winter time, which is not a favorable condition for artworks possibly present in this type of buildings. In the conservation heating strategy (Case 2) and dehumidification (Case 3) the RH indoors is in the range between 60 and $70 \%$ during the whole year, due to the control of the humidity. The indoor temperature of the dehumidifying case is the same as the outdoor temperature, while the case of the conservation heating case it is slightly higher when a decrease of the RH is needed. 

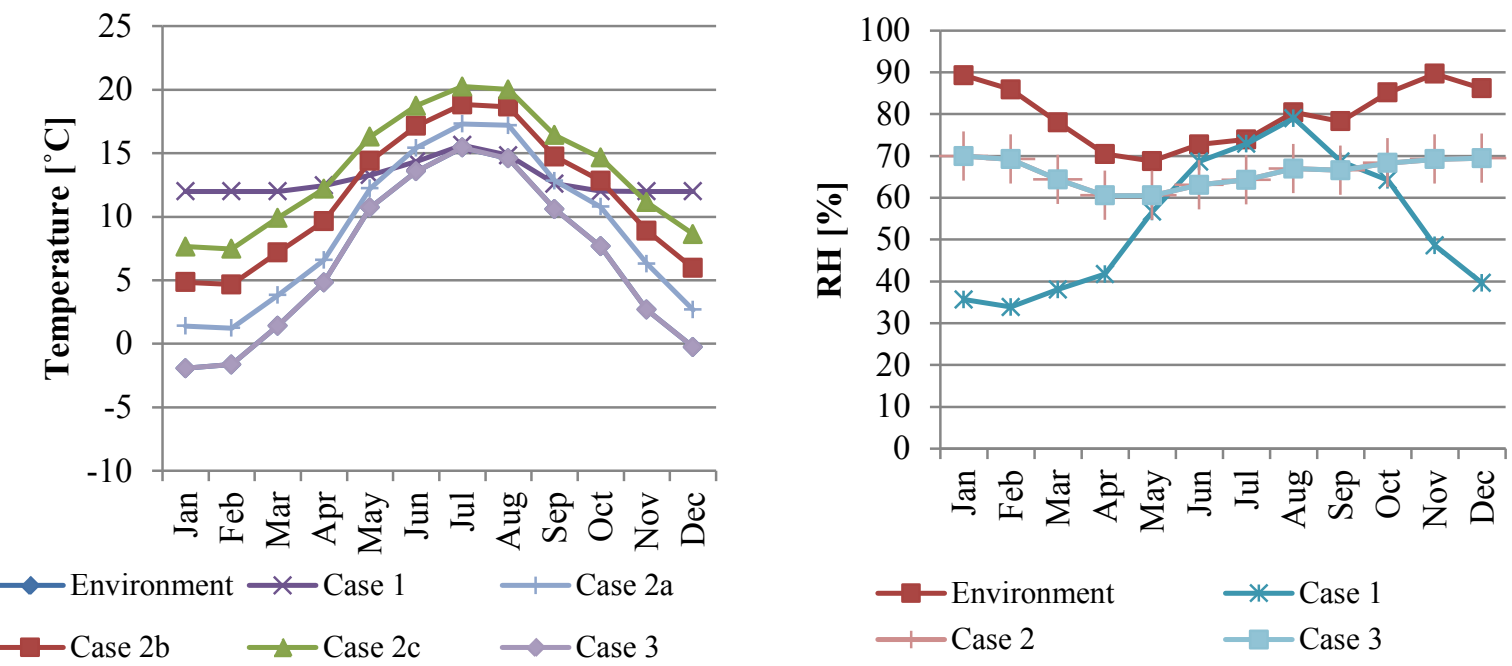

Figure 1: Monthly temperature distribution (left) and relative humidity RH (right) in the three cases in the Gothenburg simulations. Case 1 is the constant temperature heating, Case $2 a$ is the conservation heating for $\Delta v=0 \mathrm{~g} / \mathrm{m}^{3}$, Case $2 b$ for $\Delta v=1 \mathrm{~g} / \mathrm{m}^{3}$, Case $2 c$ for $\Delta v=2 \mathrm{~g} / \mathrm{m}^{3}$ and Case $3 i \mathrm{~s}$ the dehumidification.

In the Figure 2 results from the calculations for Gothenburg are presented. The exergy content for three different cases, sum of the time-steps for each month, i $\sigma$ dhown. For $\Delta \mathrm{v}=0 \mathrm{~g} / \mathrm{m}^{3}$, the exergy content in the air is significantly lower for the conservation heating and dehumidification strategies in the cold period of the year, when compared to the constant temperature strategy. In fact, in the January average conditions with an environment temperature of $-1.9{ }^{\circ} \mathrm{C}$ and $\mathrm{RH}$ of $89 \%$, the temperature necessary to keep the $\mathrm{RH}$ under $70 \%$ is $1.5{ }^{\circ} \mathrm{C}$. By heating up to $12{ }^{\circ} \mathrm{C}$ the $\mathrm{RH}$ falls to $34 \%$, which is a low level of moisture in the air at the expense of a great exergy content.

The exergy content increases for both constant heating and dehumidification strategies $\alpha \sigma \Delta v$ increases, due to the higher temperatures that must be reached in the room to decrease the relative humidity for the conservation heating and to the greater potential of chemical exergy in the dehumidification case. Yet, in the period between December and February the exergy content of the constant temperature heating is the double of the conservation heating with $\Delta \mathrm{v}=2 \mathrm{~g} / \mathrm{m}^{3}$.

In the warm season, i.e. from May until September, the exergy content of the constant heating gradually decreases, due to the increasing environment temperatures, but the relative humidity of the room in these conditions is higher than the limit value of $70 \%$.

In the warm season the exergy content of the conservation heating and the dehumidification opproach i $\sigma$ comparable for the different value $\sigma$ of $\Delta \mathrm{v}$. However, the exergy content of the air in the conservation heating cases becomes remarkably higher in the cold months, from December to March, when the environment relative humidity has the highest yearly peaks. 


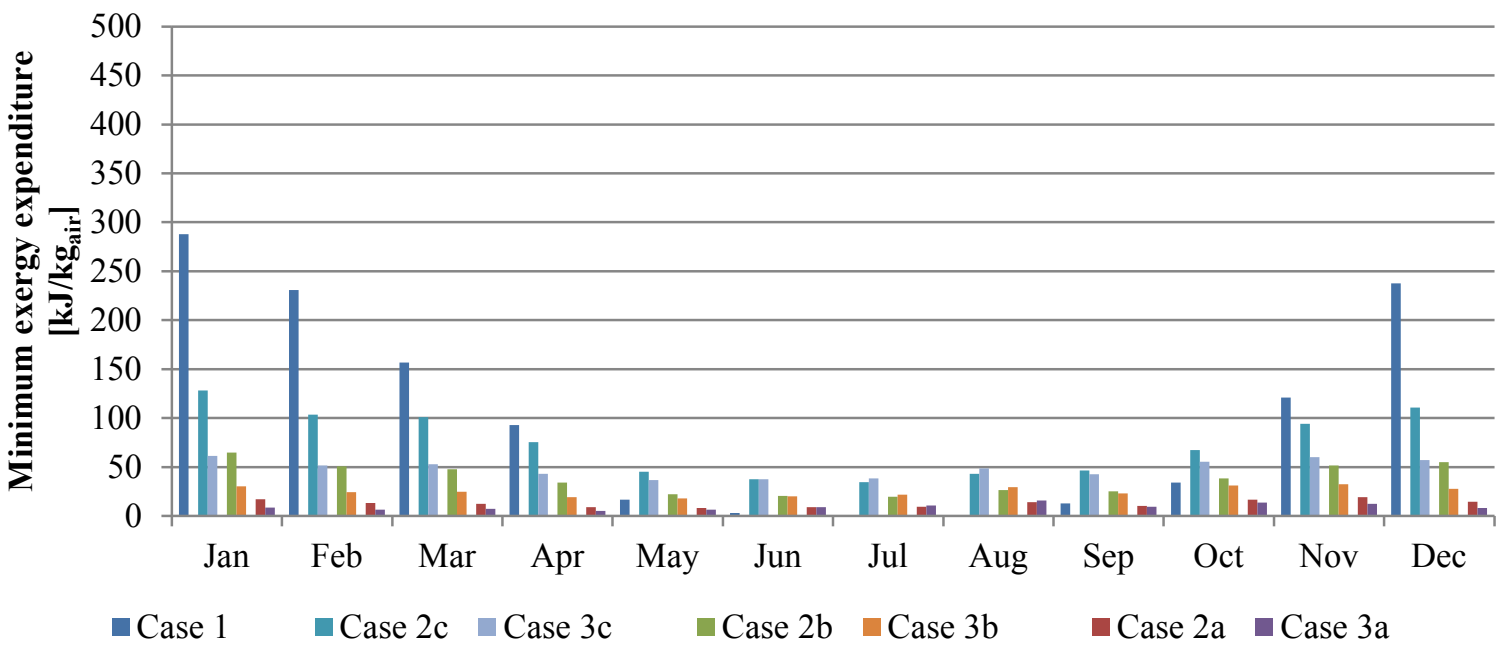

Figure 2: Comparison of the minimum exergy expenditure per $\mathrm{kg}$ of indoor air, in the Gothenburg climate. The air exergy content is the sum of the values calculated for each time-step. Case 1 is the constant temperature heating, Case $2 a$ is the conservation heating for $\Delta v=0 \mathrm{~g} / \mathrm{m}^{3}$, Case $2 b$ for $\Delta v=1$ $\mathrm{g} / \mathrm{m}^{3}$, Case $2 c$ for $\Delta v=2 \mathrm{~g} / \mathrm{m}^{3}$, Case $3 a$ is the dehumidification for $\Delta v=0 \mathrm{~g} / \mathrm{m}^{3}$, Case $3 \mathrm{~b}$ for $\Delta v=1 \mathrm{~g} / \mathrm{m}^{3}$, and Case $3 c$ for $\Delta v=2 \mathrm{~g} / \mathrm{m}^{3}$.

In Figure 3, average monthly temperatures are shown for Östersund, together with the average values for the monthly temperatures for RH. The temperature patterns are similar to the ones obtained for the Gothenburg climate, but the minimum average temperature is lower $(-5.9$ in February) than in Gothenburg (-1.9 in January). The relative humidity is also lower: the yearly average $\mathrm{RH}$ in Östersund is $74.8 \%$ while in Gothenburg is $79.9 \%$. This makes it possible that all the three approaches keep the average value of the $\mathrm{RH}$ under the $70 \%$ limit value. The temperature difference between environment and room in the cold period is greater than $15{ }^{\circ} \mathrm{C}$ in four months for the constant temperature heating case, causing the $\mathrm{RH}$ of the room to drop down to values in the range of $20-30 \%$. The range of $\mathrm{RH}$ for the conservation heating and the dehumidification are within $60 \%$ and $70 \%$ during the whole year, which is an ideal condition.
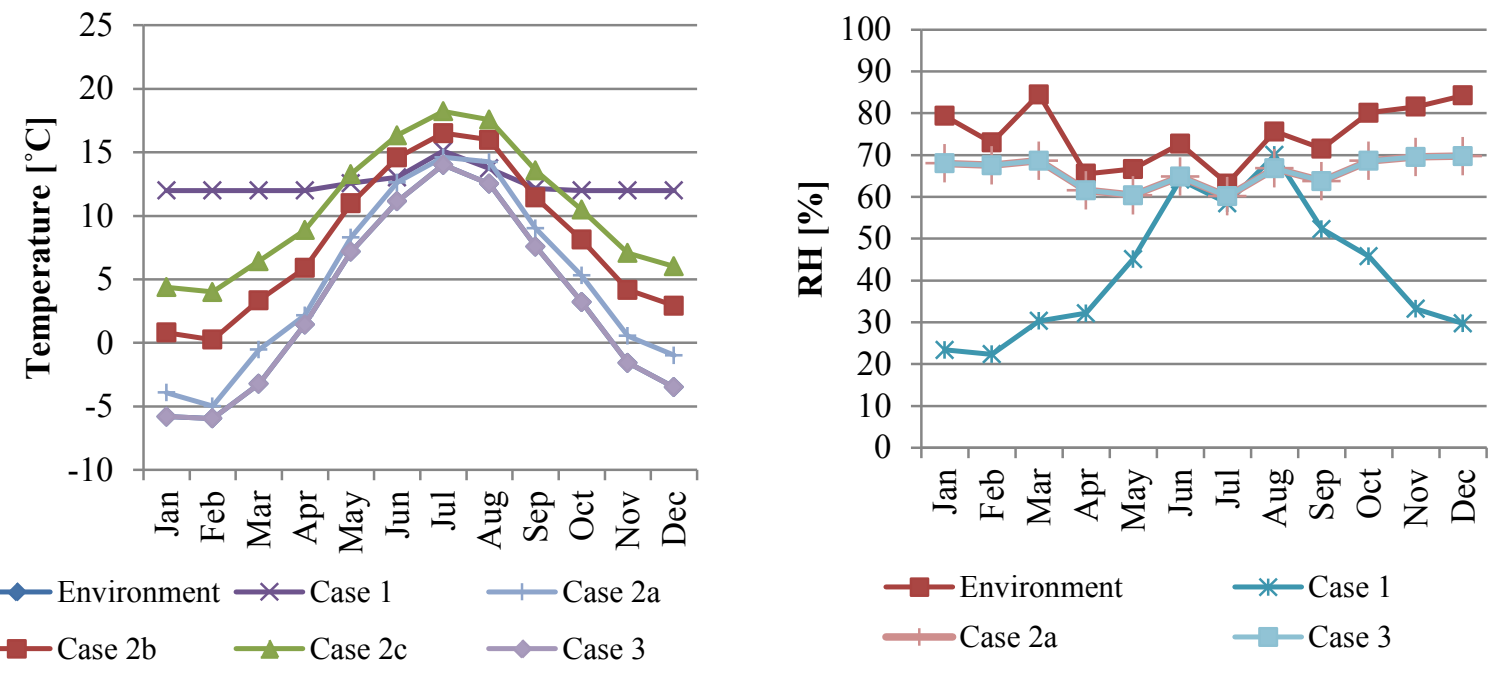

Figure 3: Monthly temperature distribution (left) and relative humidity $R H$ (right) in the three cases in the Östersund simulations. Case 1 is the constant temperature heating, Case $2 a$ is the conservation heating for $\Delta v=0 \mathrm{~g} / \mathrm{m} 3$, Case $2 \mathrm{bf}$ or $\Delta v=1 \mathrm{~g} / \mathrm{m} 3$, Case $2 c$ for $\Delta v=2 \mathrm{~g} / \mathrm{m} 3$ and Case $3 i \mathrm{~s}$ the dehumidification. 
In Figure 4, the exergy content of the room air in the different cases is shown for Östersund. In the cold season from October to March, the constant temperature heating approach has an exergy content three times higher than the conservation heating and ten times higher than the

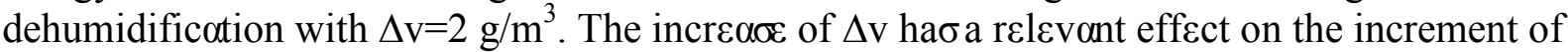
exergy content both for the conservation heating and dehumidification strategies. Similarly to the Figure 2, the exergy content is significantly lower in the cold season in the dehumidification when compared to the conservation heating, while in warmer season there is little difference between the two strategies.

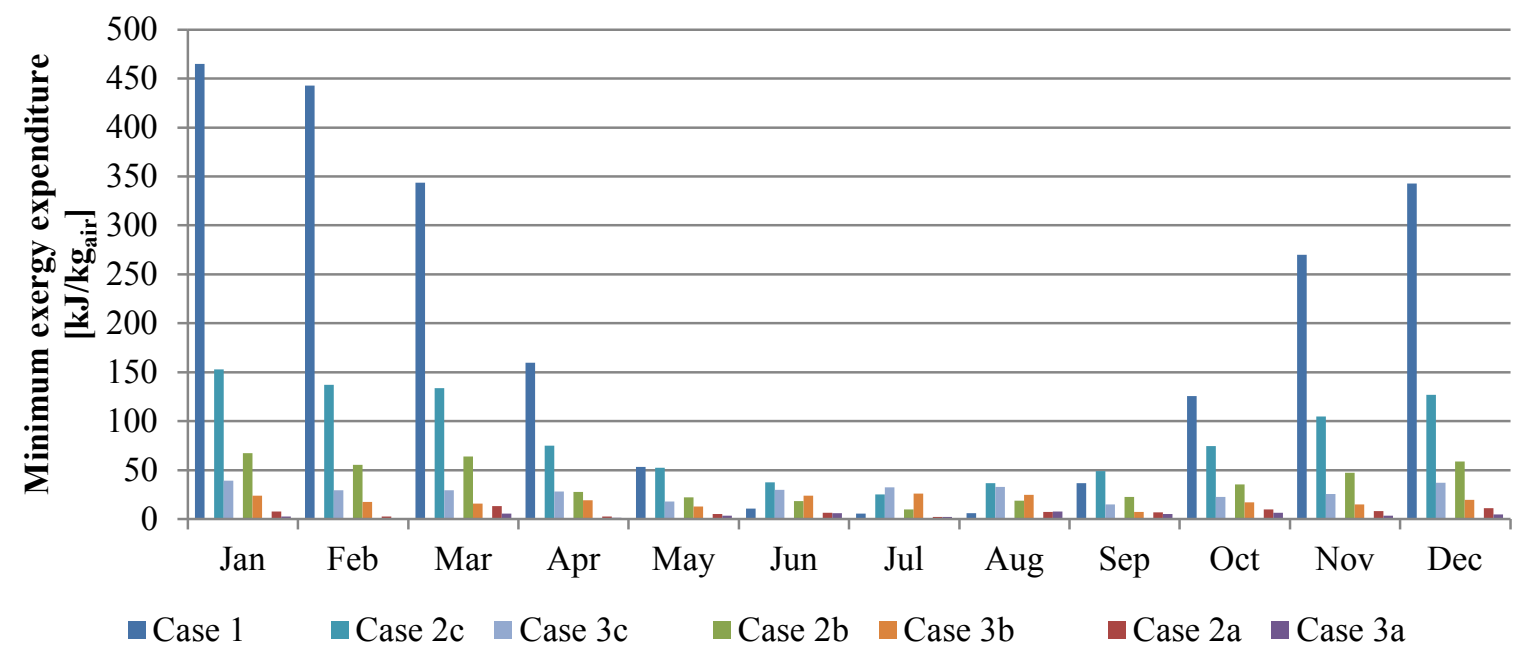

Figure 4: Comparison of the minimum exergy expenditure per $\mathrm{kg}$ of indoor air, in the Östersund climate simulation. The air exergy content is the sum of the values calculated for each time-step. Case 1 is the constant temperature heating, Case $2 a$ is the conservation heating for $\Delta v=0 \mathrm{~g} / \mathrm{m}^{3}$, Case $2 b$ for $\Delta v=1 \mathrm{~g} / \mathrm{m}^{3}$, Case $2 c$ for $\Delta v=2 \mathrm{~g} / \mathrm{m}^{3}$, Case $3 a$ is the dehumidification for $\Delta v=0 \mathrm{~g} / \mathrm{m}^{3}$, Case $3 \mathrm{~b}$ for $\Delta v=1$ $\mathrm{g} / \mathrm{m}^{3}$, and Case $3 \mathrm{c}$ for $\Delta v=2 \mathrm{~g} / \mathrm{m}^{3}$.

\section{Discussion}

For both Gothenburg and Östersund, some general trends can be highlighted.

- In the cold season the temperatures reached in the constant temperature approach are too high, causing both the RH to decrease too much, and at the same time the exergy content to increase significantly. In the warmer period it is ineffective in maintaining the $\mathrm{RH}$ under the $70 \%$ limit in one of the two cases analyzed (Gothenburg).

- The increase of the internal moisture generation $\Delta \mathrm{v}$ decreases the advantage of the conservation heating and dehumidification strategies on the constant temperature heating, due to the higher temperatures that must be reached in the room to decrease the RH and the higher moisture exergy content.

- The dehumidification approach has a significantly lower exergy content in the cold months, when compared to the constant temperature and the conservation heating approach.

- In warmer months, the difference of the exergy content between conservation heating and dehumidification is minimal 


\section{Conclusions}

In the present paper the exergy concept has been applied to explore the potential energy savings to limit the relative humidity of the air, which plays an important role in the preservation of historical buildings. Three different strategies have been simulated in two different locations in Sweden, Gothenburg and Östersund.

Constant temperature heating has proved to be inefficient and not efficacious at the same time. This strategy is not able to limit the RH under the target values and it consumes unnecessary exergy in cold periods due to the large temperature difference between the environment and the room.

In the conservation heating approach, the temperature differences between environment and

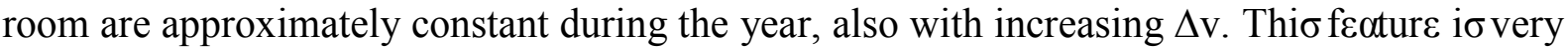
important when a heat pump is used. The coefficient of performance (COP) of a heat pump is highly dependent on the difference of temperature between condenser and evoporotor, $\Delta \mathrm{T}_{\mathrm{c} \text {-ev }}$. The omaller the $\Delta \mathrm{T}_{\mathrm{c} \text {-ev }}$, the higher is the COP of the heat pump, which makes this strategy attractive for the building heritage.

\section{References}

[1] Commission of the European Communities, Action Plan for Energy Efficiency: Realising the Potential, 2006.

[2] International Energy Agency ECBCS Annex 37, Heating and Cooling with Focus on Increased Energy Efficiency and Improved Comfort - Guidebook to IEA ECBCS Annex 37 Low Exergy Systems for Heating and Cooling of Buildings. VTT, Technical Research Centre of Finland, 2003.

[3] International Energy Agency. Low Exergy Systems for High Performance Buildings and Communities. [Online] 2005-2009, http://www.annex49.com.

[4] International Energy Agency ECBCS Annex 39, Vacuum insulation panels, study on VIP components and panel for service life prediction of VIP building applications, 2005.

[5] European Commission, Directorate General for Energy \& Transport, The new Directive on the energy performance of buildings - Moving closer to Kyoto, 2003.

[6] P. Sakulpipatsin Exergy Efficient Building Design, Doctoral Thesis, Department of Building Technology, University of Delft, 2008.

[7] M. Shukuya, A. Hammache, Introduction to the concept of exergy - For a b etter understanding of low-temperature heating and high-temperature cooling systems, VTT Research Notes, 2002.

[8] T. Broström, G. Leijonhufvud, Heat pumps for conservation heating. Proceedings of the 8th Symposium on Building Physics in the Nordic Countries. 2008, pp. 1143-1150.

[9] M. Alhazmy, Minimum work requirement for water production in humidificationdehumidification desalination cycle, Desalination, 2007, pp 102-111.

[10] P. Sakulpipatsin et al., An Exergy Application for Analysis of Buildings and HVAC systems. Energy and Buildings, 42, 2009, pp 90-99.

[11] D. Camuffo, (editor). Church Heating and the Preservation of the Cultural Heritage. Guide to the Analysis of the Pros and Cons of Various Heating Systems. Electa, 2006.

[12] A. Bejan, Advanced Engineering Thermodynamics. John Wiley, New York, 1997. 